\title{
The abundance of large, piscivorous Ferox Trout (Salmo trutta) in Loch Rannoch, Scotland
}

\author{
Alastair Thorne ${ }^{1}$ ， Alisdair I MacDonald ${ }^{1}$ ， Joseph L Thorley ${ }^{\text {Corresp. }} 2$ \\ 1 Freshwater Laboratory, Marine Scotland, Pitlochry, Scotland \\ 2 Poisson Consulting, Nelson, British Columbia, Canada \\ Corresponding Author: Joseph L Thorley \\ Email address: joe@poissonconsulting.ca
}

Background. Ferox Trout are large, long-lived piscivorous Brown Trout (Salmo trutta). Due to their exceptionally large size, Ferox Trout are highly sought after by anglers while their life-history strategy, which includes delayed maturation, multiphasic growth and extended longevity, is of interest to ecological and evolutionary modelers. However, despite their recreational and theoretical importance, little is known about the typical abundance of Ferox Trout.

Methods. To rectify this situation a 16 year angling-based mark-recapture study was conducted on Loch Rannoch, which at $19 \mathrm{~km}^{2}$ is one of the largest lakes in the United Kingdom.

Results. A hierarchical Bayesian Jolly-Seber analysis of the data suggest that if individual differences in catchability are negligible the population of Ferox Trout in Loch Rannoch in 2009 was approximately 71 fish. The results also suggest that a single, often unaccompanied, highly-experienced angler was able to catch roughly $8 \%$ of the available fish on an annual basis.

Discussion. It is recommended that anglers adopt a precautionary approach and release all trout with a fork length $\geq 400 \mathrm{~mm}$ caught by trolling in Loch Rannoch. There is an urgent need to assess the status of Ferox Trout in other lakes. 


\title{
The abundance of large, piscivorous Ferox Trout (Salmo trutta) in Loch Rannoch, Scotland
}

\author{
Alastair Thorne $^{1}$, Alasdair I. MacDonald ${ }^{1}$, and Joseph L. Thorley ${ }^{2}$ \\ ${ }^{1}$ Marine Scotland, Freshwater Laboratory, Pitlochry, Perthshire, Scotland \\ ${ }^{2}$ Poisson Consulting Ltd., Nelson, British Columbia, Canada
}

\begin{abstract}
Background. Ferox Trout are large, long-lived piscivorous Brown Trout (Salmo trutta). Due to their exceptionally large size, Ferox Trout are highly sought after by anglers while their life-history strategy, which includes delayed maturation, multiphasic growth and extended longevity, is of interest to ecological and evolutionary modelers. However, despite their recreational and theoretical importance, little is known about the typical abundance of Ferox Trout.

Methods. To rectify this situation a 16 year angling-based mark-recapture study was conducted on Loch Rannoch, which at $19 \mathrm{~km}^{2}$ is one of the largest lakes in the United Kingdom.

Results. A hierarchical Bayesian Jolly-Seber analysis of the data suggest that if individual differences in catchability are negligible the population of Ferox Trout in Loch Rannoch in 2009 was approximately 71 fish. The results also suggest that a single, often unaccompanied, highly-experienced angler was able to catch roughly $8 \%$ of the available fish on an annual basis.

Discussion. It is recommended that anglers adopt a precautionary approach and release all trout with a fork length $\geq 400 \mathrm{~mm}$ caught by trolling in Loch Rannoch. There is an urgent need to assess the status of Ferox Trout in other lakes.
\end{abstract}

Keywords: Survival, Exploitation, Bayesian, Hierarchical, Jolly-Seber.

\section{INTRODUCTION}

Due to its large size and distinctive appearance, the Ferox Trout was originally considered its own species, Salmo ferox (Jardine, 1834); an appellation that was lost when all the forms of Brown Trout were lumped into Salmo trutta. More recently, Duguid et al. (2006) have demonstrated that Ferox Trout in Lochs Melvin (Ireland), Awe and Laggan (Scotland) are reproductively isolated and genetically distinct from their sympatric conspecifics and together form a monophyletic grouping. Based on this evidence, Duguid et al. (2006) argue that the scientific name S. ferox should be resurrected.

Ferox Trout are characterized by their large size and extended longevity. The British rod caught record is $14.4 \mathrm{~kg} \mathrm{(} 31 \mathrm{lb} 12 \mathrm{oz})$ and the oldest recorded individual was estimated to be $23 \pm 1$ years of age based on scale annuli (Campbell, 1979). The consensus view is that Ferox Trout achieve their large size by forgoing spawning until they are big enough to switch to a primarily piscivorous diet at which point they experience an increased growth rate (Campbell, 1971, 1979; Went, 1979). The resultant higher survival and fecundity is assumed to compensate for the lost spawning opportunities (Mangel, 1996; Mangel and Abrahams, 2001).

Comparative lake studies (Campbell, 1971, 1979) and ecological models (Mangel, 1996; Mangel and Abrahams, 2001) indicate that Ferox Trout require a large $\left(>1 \mathrm{~km}^{2}\right)$ oligotrophic lake and an abundant population of Arctic Charr (Salvelinus alpinus). The ecological models also suggest that under such conditions, Ferox Trout should constitute approximately 5\% of the total Brown Trout population (Mangel and Abrahams, 2001). However, there is a lack of robust estimates of the abundance of Ferox Trout or assessments of the potential for angling to impact individual populations. The reasons for this knowledge gap were clearly stated by Duguid et al. (2006, p. 90)

One of the main difficulties in attempting a detailed ferox study is obtaining sufficient specimens. Ferox densities are believed to be low, and their large size and usual distribution 
deep in the water column makes angling the only practical way to obtain fish. Only a small number of ferox, however, are caught from any lake in a single year even by anglers specializing in ferox capture.

At $19 \mathrm{~km}^{2}$, Loch Rannoch, which is situated in central Scotland, is one of the largest lakes in the United Kingdom. It was chosen for the current study due to its long history of producing Ferox Trout (Campbell, 1971, 1979). Whether the Ferox Trout in Loch Rannoch are sufficiently isolated and genetically distinct to be considered a separate species (Duguid et al., 2006) is unknown. Consequently, Ferox Trout were identified based on their large size and capture method - trolled dead baits and lures (Campbell, 1971, 1979; Went, 1979; Grey et al., 2002). As well as Brown and Ferox Trout, Loch Rannoch also contains three ecologically and morphologically distinct forms of Arctic charr (Verspoor et al., 2010).

In 1994, the first author (AT) - a highly-experienced ferox angler - began tagging and releasing all Ferox Trout captured by himself or his boat companion on Loch Rannoch. He continued this practise for 16 years. The paper uses the resultant dataset to estimate the abundance of Ferox Trout in Loch Rannoch. Although the current dataset represents a unique opportunity to better understand the life history of this top-level piscivore, the data are nonetheless sparse. Consequently, they are analyzed using Bayesian methods which provide statistically unbiased estimates irrespective of sample size (Kéry and Schaub, 2011; Royle and Dorazio, 2008).

\section{METHODS}

\section{Field Site}

Loch Rannoch, which is located in Highland Perthshire (Latitude: 56.685 Longitude: -4.321), has a length of $15.1 \mathrm{~km}$, width of $1.8 \mathrm{~km}$ and a maximum depth of $134 \mathrm{~m}$. It is oligotrophic with a stony shoreline and lies in a catchment dominated by mixed relict deciduous and coniferous woodlands with areas of rough grazing and marginal cultivation. Murray and Pullar (1904) provide a more complete description of its physical characteristics.

Loch Rannoch is part of the Tummel Valley Hydro Electric generation complex and has been a hydroelectric reservoir since 1928, when Rannoch Power Station began to receive water from Loch Ericht. A low barrage at the eastern end of the loch limits the change in water level to a maximum of $2.74 \mathrm{~m}$.

As well as Brown and Ferox Trout, the loch contains at least seven other species of fish: Arctic Charr, Atlantic Salmon (Salmo salar), Pike (Esox lucius), Perch (Perca fluviatilis), Eels (Anguilla anguilla), Three-Spined Sticklebacks (Gasterosteus aculeatus) and Minnows (Phoxinus phoxinus).

\section{Fish Capture and Tagging}

Between 1994 and 2009, AT tagged and released all Ferox Trout captured by himself or his boat companion while angling on Loch Rannoch (Fig. 1). In the absence of any genetic data, a Ferox Trout was deemed to be any member of the Brown trout species complex that was caught by trolling with a fork length $\geq$ $400 \mathrm{~mm}$. A fork length of $400 \mathrm{~mm}$ was chosen as this is considered to be the upper length threshold for the inferred switch to piscivory (Campbell, 1971, 1979). All the fish were caught during the angling season (March 15 to October 6) by licensed anglers using permitted angling methods. The research was conducted within the framework of the UK 1986 Animals Scientific Procedures Act.

The Ferox Trout were angled by trolling mounted dead baits and lures behind a boat at differing depths and speeds (Greer, 1995). The dead baits (usually Brown Trout or Arctic Charr) were mounted to impart fish-like movement. An echo sounder was used to search the contours of the loch bottom for drop-offs and likely fish holding areas and to ascertain fishing depth. Typically, one entire circuit of the loch's shoreline excluding the shallow west end, which has an area of $3 \mathrm{~km}^{2}$, was undertaken on each visit.

Hooked fish were played with care and netted directly into a large tank of water before being carefully unhooked. The fish was then transferred into a large fine-mesh keep net (net pen), on the shore closest to the point of capture, where it was allowed to recover before processing. After recovering, the fish was removed from the keep net and placed in a tank containing water and anesthetic $(0.05 \%$ aqueous solution of 2-pheoxyethanol). When the fish was sufficiently sedated its fork length and wet mass were obtained. The adipose fin was then clipped to aid in the identification of recaptures. In addition, all but one fish (F63) was externally tagged using a Carlin, dart or anchor tag. The tags included the text "REWARD" and a telephone number for reporting. The reward value which was not printed on the tag was five British 


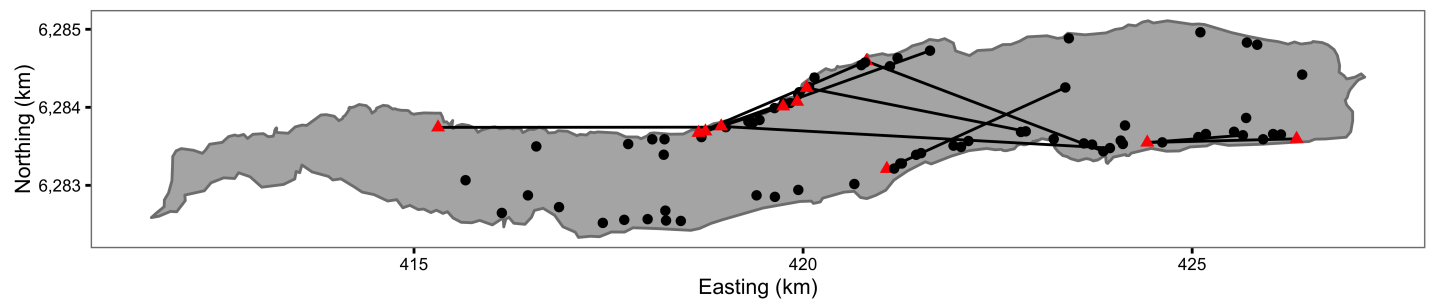

Figure 1. Map of Ferox Trout Caught by Angling on Loch Rannoch between 1994 and 2009. The 69 initial captures are indicated by black circles and the 11 inter-annual recaptures by red triangles. Consecutive recaptures of the same individual are linked by black lines. The coordinates are for UTM Zone 30N (EPSG 32630). Map data from Land Cover of Scotland data, MLURI 1993.

pounds. The type of tag used depended on which type was available at the time. After tagging, the fish was returned to the keep net to recover and then released from the shore. The entire procedure typically took less than $30 \mathrm{~min}$. The capture location was estimated using a 1:5000 map.

Five anglers, including AIM, accompanied AT on one or more occasions. On average AT spent 10 days boat angling per year for approximately 10 hours per day while fishing three rods although detailed logs of angling effort were not kept. The boat, outboard, rods, reels, line type and dead bait set-up remained constant throughout the study.

\section{Statistical Analysis}

Fish. Two fish (F53 and F58), which were both recaught once, were excluded from the study because they had a deformed spine and jaw, respectively. After the further exclusion of four intra-annual recaptures, the data set contained information on 80 encounters involving 69 different Ferox Trout (Table 1); 7 of which were recaught in at least one subsequent year.

\begin{tabular}{|c|c|c|c|c|c|c|c|c|c|c|c|c|c|c|c|c|}
\hline Captures & Year & 95 & 96 & 97 & 98 & 99 & 00 & 01 & 02 & 03 & 04 & 05 & 06 & 07 & 08 & 09 \\
\hline 7 & 1994 & 0 & 0 & 0 & 1 & 0 & 0 & 1 & 0 & 0 & 0 & 0 & 0 & 0 & 0 & 0 \\
\hline 6 & 1995 & & 0 & 0 & 0 & 0 & 0 & 0 & 0 & 0 & 0 & 0 & 0 & 0 & 0 & 0 \\
\hline 5 & 1996 & & & 0 & 0 & 0 & 0 & 0 & 0 & 0 & 0 & 0 & 0 & 0 & 0 & 0 \\
\hline 2 & 1997 & & & & 0 & 0 & 0 & 0 & 0 & 0 & 0 & 0 & 0 & 0 & 0 & 0 \\
\hline 5 & 1998 & & & & & 0 & 0 & 0 & 1 & 0 & 0 & 0 & 1 & 0 & 0 & 0 \\
\hline 2 & 1999 & & & & & & 0 & 0 & 0 & 0 & 0 & 0 & 0 & 0 & 0 & 0 \\
\hline 12 & 2000 & & & & & & & 0 & 1 & 1 & 0 & 0 & 0 & 0 & 0 & 0 \\
\hline 6 & 2001 & & & & & & & & 1 & 0 & 1 & 1 & 0 & 0 & 0 & 0 \\
\hline 3 & 2002 & & & & & & & & & 0 & 0 & 0 & 0 & 0 & 0 & 0 \\
\hline 4 & 2003 & & & & & & & & & & 0 & 0 & 0 & 0 & 0 & 0 \\
\hline 2 & 2004 & & & & & & & & & & & 0 & 0 & 0 & 0 & 0 \\
\hline 2 & 2005 & & & & & & & & & & & & 0 & 1 & 0 & 1 \\
\hline 1 & 2006 & & & & & & & & & & & & & 0 & 0 & 0 \\
\hline 1 & 2007 & & & & & & & & & & & & & & 0 & 0 \\
\hline 2 & 2008 & & & & & & & & & & & & & & & 0 \\
\hline 9 & 2009 & & & & & & & & & & & & & & & \\
\hline
\end{tabular}

Table 1. Initial Captures and Subsequent Recaptures of Angled Loch Rannoch Ferox Trout by Year.

Hierarchical Bayesian Model. The abundance, annual survival and probability of (re)capture were estimated from the mark-recapture data using a hierarchical Bayesian Jolly-Seber (JS) model (Kéry and Schaub, 2011). The model was the superpopulation implementation of Schwarz and Arnason (1996) in the form of a state-space model with data augmentation (Kéry and Schaub, 2011). Based on preliminary analyses the augmented data set was fixed at 1,000 (genuine and pseudo-) individuals. The zero-inflation 
of the augmented data set was modeled as an inclusion probability $(\psi)$. Due to the sparsity of data, the annual survival $(S)$ and the probability of (re)capture $(p)$ were assumed to be constant. The only remaining primary parameter was the probability of an individual recruiting to the population at the start of the first year $\left(\rho_{1}\right)$. The prior probability distributions for $\psi, S, p$ and $\rho_{1}$ were all uniform distributions between zero and one. The hierarchical Bayesian JS state-space model made the following assumptions:

1. Every individual in the population had the same constant probability of (re)capture $(p)$.

2. Every individual in the population had the same constant probability of surviving $(S)$.

3. Previously captured individuals were correctly identified.

4. The number of individuals recruiting to the population at the start of each year $(B)$ remained constant.

5. Sampling is instantaneous.

Parameter Estimates. The posterior distributions of the parameters were estimated using a Monte Carlo Markov Chain (MCMC) algorithm. To guard against non-convergence of the MCMC process, five chains were run, starting at randomly selected initial values. Each chain was run for at least $10^{5}$ iterations with the first half of the chains discarded for burn-in followed by further thinning to leave at least 10,000 samples. Convergence was confirmed by ensuring that the Brooks-Gelman-Rubin convergence diagnostic was $\hat{R} \leq 1.05$ for each of the parameters in the model (Brooks and Gelman, 1998; Kéry and Schaub, 2011). The reported point estimates are the mean and the $95 \%$ credible intervals (CRIs) are the 2.5 and $97.5 \%$ quantiles (Gelman, 2014).

Software. The analyses were performed using R version 3.3.1 (R Core Team, 2015), JAGS 4.2.0 (Plummer, 2003) and the ranmrdata and ranmr R packages, which were developed specifically for this paper. Article S1 provides instructions on how to download the packages and replicate the analysis.

\section{RESULTS}

Fish. The (re)captured fish varied from 400 to $825 \mathrm{~mm}$ in length and from 0.62 to $7.41 \mathrm{~kg}$ in mass (Fig. 2). Although two large recaptures appeared to senesce (as evidenced by a decline in mass with increasing length), there was no obvious effect of previous capture on body condition (Fig. 2). Tag loss was only recorded for one of the individuals: F21 on its second recapture eight years after it was initially tagged. F21 was identified from photographs of its melanophore constellations (Fig. S1-S3). F13 and F45 were recaught by non-participatory anglers. F45 was released. Both recapture events were excluded from the data, plots and analyses.

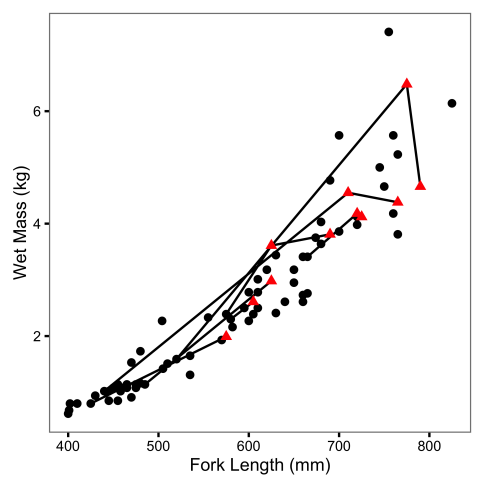

Figure 2. Mass-Length Scatterplot for Ferox Trout Caught by Angling. The 69 initial captures are indicated by black circles and the 11 inter-annual recaptures by red triangles. Consecutive recaptures of the same individual are linked by black lines. 
Parameter Estimates. The Bayesian JS mark-recapture model estimated the annual survival $(S)$ to be $0.74(95 \%$ CRI $0.57-0.89)$ and the annual probability of capture by the primary author or his companion $(p)$ to be 0.08 (95\% CRI $0.03-0.16)$. The inclusion parameter $(\psi)$ was estimated to be $0.42(95 \%$ CRI 0.23 - 0.76) while the probability of recruiting at the start of the first year $\left(\rho_{1}\right)$ was $0.26(95 \%$ CRI $0.13-$ $0.44)$. The number of individuals recruiting to the population annually $(B)$ was 21 individuals $(95 \%$ CRI 11 - 37). The abundance estimate was 111 individuals (95\% CRI 39 - 248) in 1994 and 71 individuals (95\% CRI 30 - 148) in 2009 (Fig. 3).

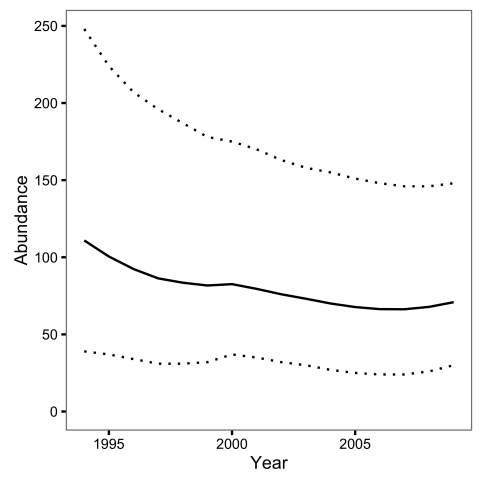

Figure 3. Loch Rannoch Ferox Trout Abundance Estimates by Year. The solid line indicates the point estimates and the dotted lines the $95 \%$ credible intervals.

Model Adequacy. The Bayesian p-value on the posterior predictive check was 0.31 which indicates that the distribution of the number of encounters (captures and recaptures) each year was consistent with the assumed constant capture efficiency.

\section{DISCUSSION}

\section{Abundance}

The JS mark-recapture model estimated that the population of Ferox Trout in Loch Rannoch declined from 111 individuals in 1994 to just 71 individuals in 2009. Whether or not the abundance estimates are accurate depends in part on the extent to which the assumption of a constant capture probability is met. The assumption can be violated in two ways: the capture probability can vary among years or it can vary among fish. Variation among years can introduce an artificial trend in the abundance estimates across the course of the study while variation among fish can cause the abundance to be over or underestimated depending on whether any individual differences are fixed (Biro, 2013) or learnt (Askey et al., 2006), respectively. Although angling logs were not kept the posterior predictive check, which compared the number of predicted versus observed encounters, statistically confirmed the relative constancy of $p$ among years. Nevertheless, individual Ferox Trout may still have differed in their vulnerability to capture by angling. As is the case for many mark-recapture studies the reliance on a single capture method and the relatively low number of encounters means it is not possible to determine the presence or form of any individual differences (Biro, 2013).

If the individual differences in catchability are negligible, the abundance estimates are unbiased and by 2009 the Ferox Trout were present at a density of just 0.044 fish.ha ${ }^{-1}$ when the shallow west end is excluded (Engstrom-Heg, 1986). For comparison, Johnston et al. (2007) estimated that the density of large piscivorous Bull Trout (Salvelinus confluentus) in the $6.5 \mathrm{~km}$ Lower Kananaskis Lake, Alberta, was 0.093 fish.ha ${ }^{-1}$ when being overexploited. In response to a zero-harvest regulation, the density of large Bull Trout in Lower Kannaskis Lake increased to over 2.6 fish.ha ${ }^{-1}$ in less than a decade. The higher density of Bull Trout in Lower Kananaskis Lake could reflect differences in lake productivity or life-history strategy.

The annual interval mortality estimate $(1-S)$ of 0.26 includes handling and tagging by the primary author and his companion as well as natural mortality and fishing mortality by all other anglers on the loch. As all fish recovered well and were only adipose clipped and marked with a single external tag, it is likely that handling and tagging effects were small. Furthermore, despite the offer of a reward only two fish 
were reported to have been recaught by a member of the public which suggests that the exploitation rate by other anglers on the loch was low. Consequently, if individual differences in catchability are negligible, $26 \%$ is probably only a moderate overestimate of the natural mortality rate. For comparison, Johnston et al. (2007) estimated the equilibrium natural mortality rate for adult Bull Trout in Lower Kananaskis Lake to be around $27 \%$.

\section{Management and Conservation Implications}

A concern for any small salmonid population is that the loss of genetic variation results in loss of adaptive potential or inbreeding depression (Wang et al., 2002). Although the levels at which the low genetic variation results in population-level consequences are difficult to predict (Vincenzi et al., 2010), the rate at which genetic variation is being lost can be calculated from the effective population size $\left(N_{e}\right)$ (Wright, 1931, 1978). Due to their mating systems and life-histories, the $N_{e}$ of most salmonid populations is considered to be around $25 \%$ of the spawning population size (Allendorf et al., 1997; McElhaney et al., 2000). Thus even if all the adult Ferox Trout in Loch Rannoch spawn in each year then this suggests that if individual differences in catchability are negligible the $N_{e}$ in 2009 was just eight. The low effective population size is concerning because an $N_{e} \geq 50$ is needed to minimize inbreeding effects and an $N_{e} \geq 500$ is required to retain long-term adaptive potential (Allendorf et al., 1997).

Whether or not the Ferox Trout in Loch Rannoch are at risk of inbreeding depression partly depends on the extent to which they are reproductively isolated from the other Brown Trout in the loch. If they, like the Ferox Trout in Lochs Melvin, Awe and Laggan, are sufficiently isolated and genetically distinct to be considered a separate species (Duguid et al., 2006) then inbreeding is likely occurring. Alternatively, if the Ferox Trout in Loch Rannoch are simply Brown Trout adopting an alternative life-history strategy, then the effective population size is a function of the total number of Brown Trout spawners and inbreeding is not an issue.

Nonetheless, even if the Ferox Trout in Loch Rannoch are not genetically isolated, a sustained high exploitation rate could result in adaptive change. Mangel and Abrahams' (2001) individual-based model predicted that the proportion of the population adopting the ferox life-history strategy is affected by mortality with high size-independent mortality being associated with no or few Ferox Trout. The explanation is straightforward; with increasing mortality the chances of benefiting from delayed maturation diminish. The potentially high catchability suggests that in the absence of catch and release even small amounts of angler effort could produce sufficient fishing mortality to select against the ferox adaptation (Hard et al., 2008).

Given the concerns associated with a potentially high exploitation rate on a long-lived, late-maturing population it is recommended that anglers adopt a conservative approach and release all trout longer than $400 \mathrm{~mm}$ caught by trolling in Loch Rannoch. There is an urgent need to assess the status of Ferox Trout in other lakes.

\section{Acknowledgments}

We thank the Loch Rannoch Conservation Association for approving the study; C. and J. Monkton for allowing access to the loch and providing a mooring; P.J. Bacon, R.A. Duguid, R. Greer, R.L. Irvine, I.A. Malcom and A.F. Youngson for feedback on earlier drafts and S. Vincenzi and two other anonymous reviewers for their helpful comments. We particularly thank the Ferox 85 group members who assisted the study.

\section{REFERENCES}

Allendorf, F. W., Bayles, D., Bottom, D. L., Currens, K. P., Frissell, C. A., Hankin, D., Lichatowich, J. A., Nehlsen, W., Trotter, P. C., and Williams, T. H. (1997). Prioritizing Pacific salmon stocks for conservation. Conservation Biology, 11(1):140-152.

Askey, P. J., Richards, S. A., Post, J. R., and Parkinson, E. A. (2006). Linking angling catch rates and fish learning under catch-and-release regulations. North American Journal of Fisheries Management, 26(4):1020-1029.

Biro, P. A. (2013). Are most samples of animals systematically biased? Consistent individual trait differences bias samples despite random sampling. Oecologia, 171(2):339-345.

Brooks, S. and Gelman, A. (1998). General methods for monitoring convergence of iterative simulations. Journal of Computational and Graphical Statistics, 7(4):434-455. 
Campbell, R. N. (1971). The growth of brown trout Salmo trutta L. in northern Scottish lochs with special reference to the improvement of fisheries. Journal of Fish Biology, 3(1):1-28.

Campbell, R. N. (1979). Ferox trout, Salmo trutta L., and charr, Salvelinus alpinus (L.), in Scottish lochs. Journal of Fish Biology, 14(1):1-29.

Duguid, R. A., Ferguson, A., and Prodohl, P. (2006). Reproductive isolation and genetic differentiation of ferox trout from sympatric brown trout in Loch Awe and Loch Laggan, Scotland. Journal of Fish Biology, 69:89-114.

Engstrom-Heg, R. (1986). Interaction of Area with Catchability Indices Used in Analyzing Inland Recreational Fisheries. Transactions of the American Fisheries Society, 115(6):818-822.

Gelman, A. (2014). Bayesian data analysis. Chapman \& Hall/CRC texts in statistical science. CRC Press, Boca Raton, third edition edition.

Greer, R. (1995). Ferox trout and Arctic charr. Swan Hill, Shrewsbury.

Grey, J., Thackeray, S. J., Jones, R. I., and Shine, A. (2002). Ferox trout (Salmo trutta) as 'Russian dolls': complementary gut content and stable isotope analyses of the Loch Ness foodweb. Freshwater Biology, 47(7):1235-1243.

Hard, J. J., Gross, M. R., Heino, M., Hilborn, R., Kope, R. G., Law, R., and Reynolds, J. D. (2008). Evolutionary consequences of fishing and their implications for salmon. Evolutionary Applications, 1(2):388-408.

Jardine, W. (1834). Observations upon the Salmonidae met with during an excursion to the north-west of Sutherlandshire. Edinburgh New Philosophical Journal, 18:46-58.

Johnston, F. D., Post, J. R., Mushens, C. J., Stelfox, J. D., Paul, A. J., and Lajeunesse, B. (2007). The demography of recovery of an overexploited bull trout, Salvelinus confluentus, population. Canadian Journal of Fisheries and Aquatic Sciences, 64(1):113-126.

Kéry, M. and Schaub, M. (2011). Bayesian population analysis using WinBUGS : a hierarchical perspective. Academic Press, Boston.

Mangel, M. (1996). Life history invariants, age at maturity and the ferox trout. Evolutionary Ecology, 10(3):249-263.

Mangel, M. and Abrahams, M. V. (2001). Age and longevity in fish, with consideration of the ferox trout. Experimental Gerontology, 36(4-6):765-790.

McElhaney, P., Ruckleshaus, M., Ford, M., Wainright, T., and Bjorkstedt, E. (2000). Viable salmonid populations and the recovery of evolutionarily significant units. Northwest Fisheries Science Center (U.S.), Seattle, W.A.

Murray, J. and Pullar, L. (1904). Bathymetrical survey of the fresh-water lochs of Scotland. Scottish Geographical Magazine, 20(1):1-47.

Plummer, M. (2003). JAGS: a program for analysis of Bayesian graphical models using Gibbs sampling. In Hornik, K., Leisch, F., and Zeileis, A., editors, Proceedings of the 3rd International Workshop on Distributed Statistical Computing (DSC 2003), Vienna, Austria.

R Core Team (2015). R: A Language and Environment for Statistical Computing.

Royle, J. A. and Dorazio, R. M. (2008). Hierarchical modeling and inference in ecology: the analysis of data from populations, metapopulations and communities. Elsevier/Academic Press, London, UK.

Schwarz, C. and Arnason, A. (1996). A general method for the analysis of capture-recapture in open populations. Biometrics, 52:860-873.

Verspoor, E., Knox, D., Greer, R., and Hammar, J. (2010). Mitochondrial DNA variation in Arctic charr (Salvelinus alpinus (L.)) morphs from Loch Rannoch, Scotland: evidence for allopatric and peripatric divergence. Hydrobiologia, 650(1):117-131.

Vincenzi, S., Crivelli, A. J., Jesenšek, D., and De Leo, G. A. (2010). The management of small, isolated salmonid populations: do we have to fix it if it ain't broken? Animal Conservation, 13(1):21-23.

Wang, S., Hard, J., and Utter, F. (2002). Salmonid inbreeding: a review. Reviews in Fish Biology and Fisheries, 11:301-319.

Went, A. E. J. (1979). 'Ferox' trout, Salmo trutta L. of Loughs Mask and Corrib. Journal of Fish Biology, 15(3):255-262.

Wright, S. (1931). Evolution in Mendelian populations. Genetics, 16(2):97-159.

Wright, S. (1978). Evolution and the Genetics of Populations: A Treatise in Four Volumes. Vol. 4, Variability Within and Among Natural Populations. University of Chicago Press, Chicago. 